\section{Relationship of Workplace stressors and Organizational Commitment: A study in the education sector}

The Journal of Educational Paradigms 2021, Vol. 03(01) 150-157

(C) Authors

ISSN (Print): 2709-202X

ISSN (Online): 2709-2038

DOI:10.47609/0301022021

\author{
Afshan Sultana ${ }^{1}$, Nauheen Syed ${ }^{2}$, Madiha Riaz ${ }^{3}$
}

\begin{abstract}
The present study investigated the relationship between organizational commitment and workplace stressors, such as work-family conflict, role conflict, and role ambiguity, and organizational injustice. Data has been collected from the education sector investigating university teachers of Faisalabad. The data was analyzed on 150 respondents through structural equation modeling (SEM), using the least-squares method. In this study, the Pearson chi-square, correlation, and regression test determine how well theoretical distributions fit the empirical distributions. The study's finding shows that the relationship between work-family conflict and organizational commitment; the work-family conflict has a significant negative relationship with organizational commitment. The teachers lack commitment due to their family responsibilities. The second purpose was to check the association between role ambiguity/role conflict and organizational commitment. The findings show a significant and positive relationship between role ambiguity/role conflict and organizational commitment. Conflicts and ambiguity in the roles make them struggle more to clear their role and prove themselves to the organization. There is a significant and positive relationship between organizational injustice and organizational commitment.
\end{abstract}

Keywords: Organizational commitment, work-family conflict, role conflict, role ambiguity, organizational injustice

Commitment could be experienced as assertiveness or mentality, where commitment develops because of meeting aims, beliefs, and improves eventually. Responsibility can be social, where it creates post affiliation, which eases the reason for persistence in an institution. Cohen (2003) has analyzed that amongst the examiners of structural and manufacturing thinking that organizational commitment has developed widespread for many years. Almost around ten years, the commitment of employees with their workers is recognized as a mental concept. Ashforth et al., (2008) examined a single aspect created on beliefs, attachment, and constancy watched in initial readings. Commitment is defined as an energy that leads a way of the act to single or multiple goals (Meyer et al., 2000).

Commitment has been hypothesized as a multilateral concept. Different aspects of responsibility differ in backgrounds, links, and significances. Particularly organizational commitment is a member's commitment to the institution. It's of dual sides, i.e., the institution's view and the member's view. Commitments grow logically and maybe a kind of association between an institution and a member or a bond with different individuals in institutions. Meyer \& Allen, 1991 pronounced the commitment of workers with their firms as "a mental condition that symbolizes member's connection with an institution and suggestions for the choice of continuity of belonging to the institution."

The ultimate property of an institution is its committed human capital. For ensuring the attachment of brilliant and knowledgeable employees with educational organizations, committed staff should be given more outstanding care. Furthermore, the school will experience loss and consequences for schooling scheme when a committed teacher leaves. Pratt, 2001; Jacob et al., (2003) However, varying campuses have different attentions and would distinctively take "excellence" (Tasopoulou et al., 2017; van Vught, 2008). At countrywide, though elements like civilizations, structures, and special interest groups (Bourdieu, 1999), have the primary function in determining graduate schools' essence. Therefore, a dissimilar working atmosphere is predicted in schools in varying countries. Despite such specific and general variances, universities overall have a single culture that facilitates free-thinking, sovereignty, contribution, and shared governance (Allen and Fifield, 1999; Rowley and Sherman, 2001).

In each university, some professors are continuously looking for information on a different basis (Bird and Allen, 1989). Three kinds of literary characters were provided by (Stiles, 2004) separatist, integrationist, and hegemonist. Which embody diverse groups of educational institutions with distinct organizational strategies, also indicated if teacher's value does not resemble the educational institution's value, it becomes difficult in this background, the study of organizational commitment is essential in higher education. Kanter, (1977) \& Voydanoff, (1980) reported that a new inspection is experienced between workers' work lives and non-work lives.

Among the work role and other life roles, conflict is a factor of work-nonwork experienced by a person. Kahn, Wolfe, Quinn, Snoek, \& Rosenthal, (1964) claimed that one-third of the men in their countrywide model is stressed by inter role conflict. However, most of the established study emphasized work role conflict, and later literature (Katz \& Kahn, 1978), sustained devoting some consideration to the changing aspects of fundamental inter role conflict. Conflict takes place in every aspect of life. Tension, produced by the burden of duties, may give poor performance because a person gives more consideration to what interests him or her. The permanent staff of an institution that upholds family is usually involved in this interesting conflict. Therefore, Work-family conflict (WFC) creates inequality in work. Family life, like family life, is affected by work or family life that affects organizational

\footnotetext{
${ }^{12}$ Department of Business Administration, Government College Women University, Faisalabad, Pakistan. Corresponding author Email: nausheen.dr@gmail.com

3 Department of Economics. Ghazi University, Dera Ghazi Khan
} 
outcomes, i.e., turnover, organizational commitment, and job satisfaction (Akintayo, 2010).

Organizational commitment remained a center of concentrated study for numerous decades (Mowday, Steers, \& Porter, 1982; Meyer \& Allen, 1991), with the stuffing of, previous conditions to, and conclusions from the perception much explored (Meyer, Stanley, Herscovitch, \& Topolnytsky, 2002). In the complex and globalized world, higher education institutions today, like trade organizations, have ethnically varied teaching staff. Because of the mixed problems faced by the HR departments in institutes of higher education, these organizations have got to have committed personnel who can adjust to transforms and convey outcomes. Against this background, it is vital to study the organizational commitment of staff in higher education. Stressors affecting organizational commitment will be studied.

\section{Literature Review of Organizational Commitment}

Michael, court \& petal, (2009) conducted an inquiry to analyze the affiliation $\mathrm{b} / \mathrm{w}$ job stress and organizational commitment. The research used three questionnaires to investigate this association. They apply this method to an Israeli educational organization. According to this research, if the employee's stress level increases, his sense of belonging to the organization decreases. But the stress doesn't influence employee's work continuance commitment. It was further revealed that employees feel loyal to the organization as they think that the doing task or work is right to do for the firm.

Salem, M., Kamarudin, \& Kadir, (2010) researched MARA colleges to conclude the impression of lecturers' view of work on organizational commitment. The study focused on the association between workers' feelings, the participation of WO in the commitment of lecturers towards an organization. A sample of 132 lecturers was selected from three different colleges of MARA. And the data was collected from them through questionnaires. Correlation and regression study have been made through statistical tools to examine the data. According to this study, the job involvement influences organizational commitment, the most $28.8 \%$ repression. The study suggested that human commitment towards the organization can be achieved by increasing job involvement and job satisfaction. In return, highly committed lecturers can make a positive contribution and increase educational institutions' effectiveness.

Abeam, (2010) researched to analyze the association between demographic aspects and job satisfaction. A model of one hundred and twenty-eight workers from service business was chosen at random to conduct the research. These workers were provided with a questionnaire to collect data. The data were evaluated using Pearson product's moment correlation coefficient and multiple regression analysis. It was interpreted that there is a significant association among organizational commitment and demographic factors like age, pay, job tenure, and supervision. This study contributed a lot to resolve the issues that influence the organizational commitment.

Anttila, (2015) conducted research to identify the things that affect commitment to the organization of the employees and to strengthen the factors that increase organizational commitment and mitigate those factors which hinder organizational commitment. To conduct the research, nine first-level managers from different company segments named Finnish multinational industrial company. The information was gathered employing interviews and surveys. As per this research, the study results can be separated into three groups, i.e., the first category consists of those factors directly related to the company. The second category consists of factors that affect the work community, and the third category consists of factors related to work characteristics. According to this research, community and work characteristics can have a significant influence on a commitment to an organization.

Kelly, (2015) research to know the relationship between commitment to organization and job satisfaction. It is a general observation that a low level of satisfaction can cause employees to voluntarily be ceasing jobs. Sixty-two employees from grade c2 to c6 were selected randomly. The sample consists of both male and female staff between the age of 22 and 29. A questionnaire was distributed among these employees to ask questions regarding pay, promotion, nature of work, co-workers, and supervision. From the questionnaire, it was interpreted employees are moderately pleased with promotion opportunities followed by the pay they receive, co-workers, and the work. The study revealed that there is a below-average level of organizational commitment among all the workers.

Further, it has been revealed that there is a strong positive relationship between organizational commitment and job satisfaction. According to this research results, there is no modification in commitment to organization and employee satisfaction related to jobs for both males and females. Still, the degree of job satisfaction and organizational commitment varies for different occupational classes.

Bahrami, et al., (2016) directed investigation to analyze the connection among promise to an organization and organizational atmosphere. The research was conducted in two teaching hospitals in yazdiran. A sum of 90 nurses was chosen through stratified accidental sampling. The questionnaire was used to collect the required data. SPSS 20 statistical software was used to analyze the obtained data and the Pearson correlation coefficient. At last, the results of the study showed that there is a desirable association between the climate of the organization and the commitment to the firm. So, by improving organizational climate, organizational commitment can be enhanced.

Ozdem, and Sezer (2019) researched to analyze result-based school management's association with organizational cynicism, commitment to an organization, and teacher's work pleasure. To conduct the research, 246 teachers from different schools were selected using random cluster sampling. A solution-focused school leadership degree has been utilized to gather the essential data, managerial sarcasm scale, organizational commitment scale, and short form of the Minnesota job satisfaction scale. According to the consequences, teachers have a high degree of commitment to institutions and have a satisfying degree of work pleasure. It was also interpreted that there is a significant favorable association among teachers' commitment to the organization and school principal's solution-focused leadership. Moreover, there is also a confident association between the school's principal focused guidance and teachers work a pleasure. The outcomes also concluded that teachers perceive school principals as the solution-focused school leaders.

\section{Work-family conflict}

Akintayo, (2010) explained the influence of work-family role conflict on organizational commitment of Nigeria employees of 
industries. The research technique used in this study was a descriptive survey. A sum of 247 sample size was chosen for the research using a balanced stratified sampling method. Tools used to gather information were: Scales of work-family disagreement and organizational commitment. To check the hypothesis created for the research, linear regression analysis and t-test were used at 0.05 alpha levels. According to the outcomes, a significant association was found between jobfamily disagreement and organizational commitment.

The results also contained a significant distinction among married and unmarried respondent's understanding of workfamily disagreement. Furthermore, it was found that men and women are having a substantial distinction in organizational commitment on the bases of work-family conflict. The study results, organizational support program was suggested to initiate and give to all stages of employees to get reduced the load of work-family conflict and practically provoked commitment in their works. The researcher said that the employee's responsibility in the family must be judged while giving duties and post to promote organizational commitment. A significant but negative association among job-family disagreement and organizational commitment was found in the findings of the study of employees functioning in industries of Nigeria.

Rehman, and Waheed, (2012) inspected the impact of workfamily disagreement on the organization's commitment to government and non-government universities of Pakistan. The study also significantly concluded work-family conflict and the level of distinction among male and female, unmarried and married persons, and staff of government and non-government universities. Seventy-two respondents filled scales of workfamily disagreement and commitment to the organization. A negative influence of work-family conflict was found through regression analysis on a commitment to the organization. The hypothesis of 3-way ANOVA exposed that wedded staff has a significant work-family disagreement compared to unmarried staff members. Furthermore, there was no considerable variation among men and women or government and non-government respondents, which were insignificant.

Jenitta, and Periyathampy, (2013), since institutions try to assist workers in handling the stability among job and home requirements, many studies are about job-home disagreement. The reason for this study was identifying association among jobhome conflict and organizational commitment amongst bank employees in the Trincomalee region. This was about to check the impact of job-home disagreement and home-job disagreement on a commitment to the organization. Fifty-six participants were gathered at random from one hundred and fourteen persons employed as managers, management learners, and personnel helpers in the Trincomalee region. Results showed that work-family disagreement has a considerable negative influence on organizational commitment.

\section{Role of Ambiguity and Role of Conflict}

Koustelios, Theodorakis, and Goulimaris, (2004) showed that this research inspects role ambiguity, role conflict and job fulfillment between Greek substantial learning educators and the amount to that the role ambiguity role conflict expects work contentment. A total participant of the samples of 61 considerable learning educators was working in the Greek "Game for everyone" programs. The standard multiple regression tests display that role ambiguity and role conflict are optimistic analysts of work contentment. This article determines with recommendations focused on the overall Secretariat of Games in Greece by an outlook to reshaping the effort of substantial learning educators in "Game for everyone" programs.

The discoveries recommended that role ambiguity and role conflict are connected to the precise characteristics of work contentment. The substantial learning educator was gratified himself, management, operational situations, and institution through the concern to work contentment. They were unhappy with their income and promotion chances. Stated that some discoveries related work on contentment between educators in primary and secondary institutes in Greece. They find that professors were happy with work himself a random cluster of the work but were unhappy by their income and promotion chances.

\section{Organizational Injustice}

According to Marín, Grzywacz, Arcury, Carrillo, Coates, \& Quandt, (2009) personals 250,000 were working in chick dealing out, the most hazardous factories of America. Such tasks were carried out by settler personals, who were often without documents, unaware of employee's privileges in the workplace's safety, and who were unwilling to follow their human rights. These circumstances created the perspective of organizational injustice, made able to be seen through rude managerial activities, and led to states in which work-related sickness and wounds could happen. This study illustrates information composed throughout the study stages supported participative research and societal fairness scheme.

Two hundred survey interviews and 26 in detail interviews were gathered in agents, a societal-based model in western North Carolina. Studies explained relations among one phase of organizational injustice, offensive management, and employee damages. Outcomes of employee's insulting management are related to different definite and summing up healthiness symbols. The relationships were strong for ladies than for gents. These recommend that more command inside the workplace might be the origin of damages and sickness. Three kinds of authority associations were discussed, which figure the foundation for the rude relations in the workplace: civilization (American vs. Latino), migration class (legal vs. illegal), and status (boss vs. employee). Two elements change these associations: relationship (partiality and rights for family) and sex.

\section{Theoretical Framework}

This study's research model shows the main variables in which the independent and dependent variables are included. The three variables are independent in which the WFC, work ambiguity/work conflict, and organizational injustice are included. On the other side, the organizational commitment is a dependent variable. This study is conducted to examine the association between them

\section{Research design}

The nature of research is descriptive. The quantitative approach was used to do this research. The method that is mostly used to solve the research problem related to social matters is quantitative methods because, with this method's help, we can quickly achieve the purpose of study more easily (Bell, \& Breyman, 2007). The questionnaire was used because the nature 
of research is descriptive, and we also used quantitative methods.

\section{Research methodology}

Focused people of current research include of all teachers of 3 government universities of the Faisalabad region. These universities are, Government College University Faisalabad, Government College Women University Faisalabad, \& Agriculture University Faisalabad. These universities are selected for the process of data collection purposes. They all are recognized as best universities. A sample of 150 teachers from three different universities is chosen for the data collection process, and this is the actual sample size for this study.

Information for this research was collected with the help of a survey. The survey is always recognized as one of the best techniques to collect the data when using the quantitative approach. To select the data more easily or also in a short period, we always carry out the research survey. Information is gathered utilizing questionnaires that include close-ended questions. Data is collected using self-survey using questionnaires.

The questionnaire is composed of 2 components. The 1 st part of the questionnaire is about demographic factors. While the 2 nd part of the survey is connected to the independent, and dependent variables, there are close-ended questions in the instrument and used to analyze workplace stressors, i.e., Workfamily conflict, role ambiguity, and role conflict \& Organizational Injustice with organizational commitment. All answers are considered on a 5-point Likert scale. Scale, i.e., Strongly disagree, Disagree, Neutral, Agree, strongly agree.

\section{Measures}

Demographic related questions in the questionnaire include, the gender of respondents, age of respondents, education of employees in universities, a designation of survey participants, and duration of their job experience. Two categories are mentioned to measure the gender male or female. The age of respondents arranged in sequence, like from 20-30, 31-40, 4150 . The next primary variable in the demographic section is the education of employees, which are also the participants of the research survey. It is divided into three main categories: started from the masters, on second, MS/MPhil, and the last one is Ph.D. The next one in this head is the job experience of employees. The demographic head's final variable is their job designations, which are measure with the help of these categories like an Assistant professor, lecturer, visiting teachers, and teaching assistants.

\section{Organizational commitment}

Organizational commitment is the dependent variable. To measure this variable, nine questions have been used, which were wholly adapted from the research (Allen, \& Meyer, 1991).

\section{Work-family conflict}

Work-family conflict is an independent variable for this research. To inspect this term or variable of study 5 questions are adapted from the analysis (Zhang, Punnett, \& Nannini, 2017).

\section{Role ambiguity and Role conflict}

Role ambiguity and Role conflict are independent variables of this study. Five items are adapted from the research to inspect role ambiguity and role conflict (Rizzo, House, \& Lirtzman, 1970). Every item has 5-point Likert responding scale (1. strongly disagree, 2. disagree, 3. nutral, 4. agree, 5. strongly agree).

\section{Organizational Injustice}

Organizational injustice is an independent variable. We have five questions taken from the study (Colquitt, 2001).

\section{Results}

Table 4.1 indicates that the total number of survey participants were 150 . And 32.7 percent of respondents were male, and 67.3 percent of the survey respondents were female participants, which shows that the strength of female respondents is greater than the strength of male employees of universities, which are respondents of the survey.

Table 4.2 illustrates the age of participants. A total of 150 employees from different universities were selected for data collection purposes. Out of which 76 participants with $50.7 \%$ were from 20-30 age groups, 31-40 age groups have 58 respondents with $38.7 \%$. The 16 respondents, with $10.7 \%$, were from the 41-50 age group.

Table 4.3 demonstrates the highest academic qualification of participants. The $8.7 \%$ noted for the participants who have their master's degrees. $64.7 \%$ of participants were those who completed their MS/MPhil degrees. And the remaining $26.7 \%$ of respondents of the survey were recognized as a Ph.D. holder. So, the highest percentage was noted for MS/MPhil.

Table 4.4 explains that 150 respondents, 68.0 percentage, was noted for respondents who have been functioning for 1-5 years in the institute. 18.7 percent of respondents working for 6-10 years in the organization, 8.7 percent of the respondents have been working for 11-15 years. 4.7 percent of the respondents have 16 to 20 years of job experience.

Table 4.5 informs about $16.7 \%$ of participants were assistant professors, 53.3 percent were lecturers, 14.7 percent were visiting lecturers, and 15.3 percent were teaching assistants.

This statistic involves the mean and standard deviation of the main variables.

The above table 4.6 demonstrates that the value of mean "I am quite aware of what I have to do" is 3.8267 , and its standard deviation is .92502 . The mean value of "I don't think that moving from one organization to another organization is immoral" is 3.8133 , and its standard deviation is .83856 . The average of "I get pleasure from talking about my organization with people outside it" is 3.7067 , and a standard deviation for it is .99358. The average of "I feel that this organization's problems are my own problem" is 3.6800 , and its standard deviation is .85389. "Has (he/she) delivered the information on time?" has an average of 3.6667 and 1.10925 as a standard deviation.

The mean value for "Explanation is clear of what has to be done." is 3.6400 and has a standard deviation of 1.04451 . The mean value for "Clear, planned goals and objectives for my work." is 3.6133 and a standard deviation of .88830. "Many things in my life would be interrupted if I decided I wanted to leave my organization now" has an average 3.6000 and standard deviation .88991. "Has (he/she) respectfully treated you?" has an average value of 3.5800 and a standard deviation of .96426 . The mean value of "I feel that I have very few options to think about leaving this organization" is 3.5667, and the standard deviation is for it is .99270 . The average of "I have sufficient time to finish my task" is 3.5133 , and its standard deviation is 1.06649 .

"To go from this organization would not be easy for me in this time, even if I wanted to" has a mean value of 3.5000 and a 
standard deviation of .98137 . The mean for "I receive a task without sufficient resources and equipment to perform it" is 3.4067 , and the standard deviation is 1.21565 . The average of "According to me nowadays people are moving from company to company very frequently" is 3.3400 and the standard deviation is 1.02210. The mean value of "Does your outcome match your contribution to the organization?" is 3.3067 , and the standard deviation is 1.29504 .

The average of "My family and friends don't like how much I am thoughtful about my work whereas I am at home." is 3.2867 , and the standard deviation is 1.16052 . The mean of "I would be very pleased to spend the rest of my career with this organization" is 3.2733, and its standard deviation is 1.02908 . The average of "Does your outcome match the exertion you have put into your job?" is 3.1600 , and the standard deviation is 1.12971. The mean value of "I would not feel it was right to leave my organization even if I got another offer for a better job elsewhere" is 3.1533, and the standard deviation is .99486 . The average of "Have the procedures been free of bias?" is 3.0933 , and the standard deviation is .99223 . The mean value for "I have too much things to do on the job that takes away from my personal interest" is 3.08000 , and the standard deviation is 1.05245 . The average of "Much exhausted to do several things I'd like to do after I come home" is 2.5867 , and the standard deviation is 1.18823 .

\section{Correlations}

The association amongst both dependent and independent variables on each other is called correlation. The table given below shows the values of the coefficients of correlation. Pearson correlation shows the relationship among variables. Table 4.7 shows that work-family conflict has negative (0.062 ) relation with organizational commitment. Table 4.8 represents that role ambiguity/role conflict has a positive (0.532) association with organizational commitment. Table 4.9 displays that organizational injustice has positive (0.458) relation with organizational commitment.

\section{Regression Analysis}

Table 4.10 shows the $\mathrm{R}$ square, which indicates the change in the dependent variable due to the presence and change of independent variables. The R2 value is .320, which means that the organizational commitment changes due to the $32.0 \%$ of the change in independent variables or independent variables.

Table 4.11 illustrates the ANOVA testing; basically, this test shows that the model of research is significant or not. The value of Sig is .000 , which indicates that the model is significant. The 4.12 table explains the value, which explains that the WFC has .015 value, which shows that WFC has a substantial impact on organizational commitment. The RA has .000 value, which also indicates a significant effect on the organizational commitment, and the OI has .040 value, which is also substantial.

\section{Reliability Test}

The above table represents the Cronbach's alpha of scales: OC (9 questions), WFC (3 items), RA/RC (5 items), OI (5 items). Every scales value varied from .778 to .896 , showing extremely excellent interior constancy with this sample. Hence, the measurement level consists of reliable variables to protect the sense of the built model. The Cronbach's alpha standards are pretty responsive to the total quantity of questions used in the scale pallant(2007). Bryman and Cramer (2005) explained that typically the Cronbach's alpha of multidimensional arrangement is low. Theoretically, Cronbach's alpha is a coefficient of reliability. It is not a statistical test (Hair et al. 2006).

\section{Conclusion}

This research work aimed to evaluate "the relationship between workplace stressors, i.e., Work-Family Conflict, Role ambiguity/Role conflict, and Organizational Injustice with Organizational Commitment." Three hypotheses were created. This study was performed in Faisalabad's educational area and the staff members of three main public universities (i.e., Agriculture University of Faisalabad, Government College University of Faisalabad, and the Government College Women University of Faisalabad) were selected as the target population. A questionnaire has been used in research, and to know reactions a five-point Likert scale was used in the questionnaire. A descriptive method has been utilized for the explanation of demographic variables. The participants' demographic traits proved that majority of the participants of this research were female, ranging from 25-40 years of age limit (67.3\%). Majority of participants wherein the range 20-30 years of age limit $(50.7 \%)$. Most of the participants were having MS/Mphil degrees (64.7\%). Most of the respondents worked in the organization for a duration of between 1-5 years (68\%).

Most of the respondents were on the post of lecturers (53.3\%). A Reliability test has been used to check the stability of the questionnaire through Cronbach's alpha. The descriptive statistics section, arithmetic mean, and standard deviation were calculated to explain the normal reactions of participants on the variables of the research. Linear regression has been used to test the research hypotheses that authenticated hypotheses $\mathrm{H} 1, \mathrm{H} 2$, and H3. Detailed results of the hypothesis are given below in the table:

\section{Discussion}

The planned research questions of the research; What is the relationship between work-family conflict and organizational commitment? What is the relationship between role ambiguity or role conflict and organizational commitment? What is the relationship between organizational injustice and organizational commitment?

The result shows that work-family conflict is significantly and negatively related to organizational commitment. This result is constant with earlier research (Akintayo, 2010), explained the influence of work-family role conflict on the organizational commitment of Nigeria employees of industries. The research technique used in this study was a descriptive survey. A sum of 247 sample sizes was chosen for the research employing a balanced stratified sampling method. Tools used to gather information were: Scales of work-family conflict and organizational commitment. To check the hypothesis created for the research, linear regression analysis and t-test were used at 0.05 alpha levels. A significant but negative relationship between work-family conflict and organizational commitment was found in the results of the study of employees working in industries if Nigeria.

The results show that role ambiguity or role conflict is significantly positively related to organizational commitment. This result is consistent with the previous study in which both positive and negative effects can be found on commitment due to ambiguity of role and conflict of role (Fatima, \& Rehaman, 2012). Research assistants are known for their main role in producing research outcomes and to support research in HEIs. 
In the first stage, this research focused on the roles of teaching assistants in different systems (HEIS is the case). Therefore, the impact of the ambiguity and conflict of role that pleasure and plan to run off was studied. The sample of 120 teaching assistant, from different universities of Rawalpindi and Islamabad, is considered.

The result showed that satisfaction and intention to leave both positively and negatively affected these roles. Universities are supposed to give the research assistant confidence by providing facilities, resources, and monetary term assistantship. The results also show that employees are not obvious about their role as there are ambiguity and conflict in the role which affect their performance by lowering their satisfaction level. If these kinds of factors remain for the long term, it may result in drastic change, and in the end, the employees quit their job. The results showed that organizational injustice is significantly positively related to organizational commitment. This result rejected the hypothesis $\mathrm{H} 3$ of the study. It was assumed a negative relationship is found between organizational injustice and organizational commitment since no previous study is found on organizational injustice with organizational commitment.

\section{Implication of the Study}

The current study would generate distinctive addition in the research of workplace stressors (work-family conflict, role ambiguity/role conflict, and organizational injustice) on organizational commitment. This research gives the outcome that staff members in the educational sector have the pressure of work-family conflict that negatively affects their commitment to the organization as most of the respondents were female and were facing many complications on the job due to family responsibilities. Role ambiguity /Role conflict has a positive relationship with organizational commitment even though the respondents have complications on their job, but they are still committed because they need the job. Organizational injustice also has a positive relationship with organizational commitment. Despite facing injustice at universities, the teachers were always committed to the organization.

\section{Limitation and future direction}

Some limitations have been found for this study. 1st is the need for time and resources. The next limitation of this research is the convenient sampling technique of gathering information that may produce partial outcomes so that findings could not be universal. Another limitation is the less welcoming reaction of participants as university teachers have many work necessities and have no long time to answer. This research has been conducted in 3 universities of the Faisalabad region because of not having enough resources. The third hypothesis of this study, H3, was rejected. Potential researchers can revise that relationship in the same or different sectors more appropriately and can be examined in other geological areas from where the correct information could be gathered. Potential investigators would do demographical research of this model.

\section{References}

Akintayo, D. I. (2010). Work-family role conflict and organizational commitment among industrial workers in Nigeria. International Journal of Psychology and Counselling, 2(1), 1-8.

Meyer et al., (2001). Construct validation in organizational behavior research: The case of organizational commitment.
In Problems and solutions in human assessment (pp. 285314). Springer, Boston, MA

Allen, D. K., \&Fifield, N. (1999). Re-engineering change in higher education. Information Research, 4(3), 4-3.

Anttila, E. (2015). Components of organizational commitmentA case study consisting managers from Finnish industrial company (Master's thesis).

Bird, B. J., \& Allen, D. N. (1989). Faculty Entrepreneur/Ship in Research University Environments. The Journal of Higher Education, 60(5), 583-596.

Cohen, A. (2003). Multiple commitments in the workplace: An integrative approach. Psychology Press.

Colquitt, J. A. (2001). On the dimensionality of organizational justice: A construct validation of a measure. Journal of applied psychology, 86(3), 386.

Jacob, M., Lundqvist, M., \& Hellsmark, H. (2003). Entrepreneurial transformations in the Swedish University system: the case of Chalmers University of Technology. Research Policy, 32(9), 1555-1568.

Kahn, R. L., Wolfe, D. M., Quinn, R. P., Snoek, J. D., \& Rosenthal, R. A. (1964). Organizational stress: Studies in role ambiguity and conflict.

Kanter, R. M. (1977). Work and family in the United States: A critical review and agenda for research and policy. Russell Sage Foundation.

Katz, D., \& Kahn, R. L. (1978). The social psychology of organizations (Vol. 2, p. 528). New York: Wiley.

Kelly, J. (2015). The relationship between organisational commitment and job satisfaction of commissioned officers within an arm of the South African National Defence Force.

Koustelios, A., Theodorakis, N., \&Goulimaris, D. (2004). Role ambiguity, role conflict and job satisfaction among physical education teachers in Greece. International Journal of Educational Management, 18(2), 87-92.

Marín, A. J., Grzywacz, J. G., Arcury, T. A., Carrillo, L., Coates, M. L., \&Quandt, S. A. (2009). Evidence of organizational injustice in poultry processing plants: possible effects on occupational health and safety among Latino workers in North Carolina. American journal of industrial medicine, 52(1), 3748.

Meyer, J. P., Stanley, D. J., Herscovitch, L., \&Topolnytsky, L. (2002). Affective, continuance, and normative commitment to the organization: A meta-analysis of antecedents, correlates, and consequences. Journal of vocational behavior, 61(1), 2052.

Meyer, J. P., \& Allen, N. J. (1991).A three-component conceptualization of organizational commitment. Human resource management review, 1(1), 61-89.

Michael, O., Court, D., \& Petal, P. (2009).Job stress and organizational commitment among mentoring coordinators. International Journal of Educational Management, 23(3), 266-288.

Mowday, R. T., Porter, L. W., \& Steers, R. M. (1982). Employee Organization Linkages: The Psychology of Commitment, Absenteeism, and Turnover, Academic Press, New York, p. 27.

Ozdem, G., \&Sezer, S. (2019). The Relationship between Solution-Focused School Leadership and Organizational Cynicism, Organizational Commitment and Teachers' Job 
Satisfaction. International Journal of Progressive Education, 15(1).

Pratt, J. (2001). Changing patterns of diversity in Europe. Lessons from an OECD study tour. lume 13, No. 2 Higher Education Management, 13(2).

Rehman, R. R., \&Waheed, A. (2012). Work-Family Conflict and Organizational Commitment: Study of Faculty Members in Pakistani Universities. Pakistan Journal of Social \& Clinical Psychology, 9(2).

Salem, M., Kamarudin, H., \&Kadir, M. B. A. (2010). Factors affecting organizational commitment among lecturers in higher educational institution in Malaysia.

Shusterman, R. (1999). Bourdieu: A critical reader.

3.1 Theoretical Framework: -

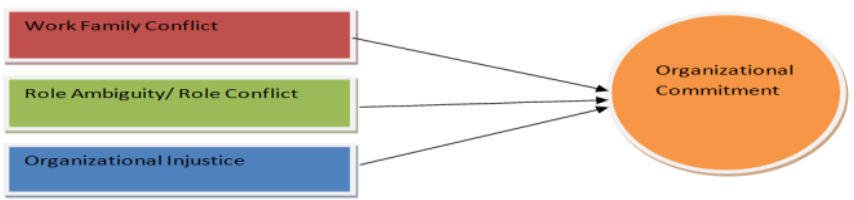

Stiles, D. R. (2004). Narcissus Revisited: The Values of Management Academics and their Role in Business School Strategies in the UK and Canada. British Journal of Management, 15(2), 157-175.

Tasopoulou, K., \&Tsiotras, G. (2017). Benchmarking towards excellence in higher education. Benchmarking: An International Journal, 24(3), 617-634.

Van Vught, F. (2008). Mission diversity and reputation in higher education. Higher Education Policy, 21(2), 151-174.

Voydanoff, P. (1980). implications of work-family relationships for productivity. Work in America Institute.

Figure\#1 Relationship model/ Research model

Table 4.1: Descriptive Statistics

\begin{tabular}{lcc}
\hline Gender & Frequency & Percentage \\
\hline Male & 49 & 32.7 \\
Female & 101 & 67.3 \\
Total & 150 & 100 \\
\hline
\end{tabular}

Table 4.2: Descriptive Statistics

\begin{tabular}{lcc}
\hline Age & frequency & percentage \\
\hline $20-30$ & 76 & 50.7 \\
$31-40$ & 58 & 38.7 \\
$41-50$ & 16 & 10.7 \\
Total & 150 & 100.0 \\
\hline
\end{tabular}

Table 4.3: Descriptive Statistics

\begin{tabular}{|c|c|c|}
\hline qualification & frequency & percentage \\
\hline Masters & 13 & 8.7 \\
\hline MS/ MPhil & 97 & 64.7 \\
\hline Ph.D. & 40 & 26.7 \\
\hline Total & 150 & 100.0 \\
\hline Time-period & Frequency & Percentage \\
\hline $1-5$ & 102 & 68.0 \\
\hline $6-10$ & 28 & 18.7 \\
\hline $11-15$ & 13 & 8.7 \\
\hline $16-20$ & 7 & 4.7 \\
\hline Total & 150 & 100.0 \\
\hline Designation & frequency & Percentage \\
\hline Assistant professor & 25 & 16.7 \\
\hline Lecturer & 80 & 53.3 \\
\hline Visiting lecturer & 22 & 14.7 \\
\hline teaching assistant & 23 & 15.3 \\
\hline Total & 150 & 100.0 \\
\hline
\end{tabular}

Total

Table 4.6: descriptive statistics

I am quite aware of what I have to do

I don't think that moving from one organization to another organization is immoral

I get pleasure from talking about my organization with people outside it

I feel that the problems of this organization are my own problem

Has (he/she) delivered the information on time?

Explanation is clear of what has to be done.

Clear, planned goals and objectives for my work.

Many things in my life would be interrupted if I decided I wanted to leave my organization now

Has (he/she) treated you in a respectful way?

I feel that I have very few options to think about leaving this organization

I have sufficient time to finish my task

To go from this organization would not be easy for me in this time, even if I wanted to

I receive a task without sufficient resources and equipment to perform it

According to me now-a-days people are moving from company to company very frequently

Does your outcome match your contribution to the organization?

My family and friends don't like how much I am thoughtful about my work whereas I am at home

\begin{tabular}{ccc}
$\mathbf{N}$ & Mean & Std. Deviation \\
\hline 150 & 3.8267 & .92502 \\
150 & 3.8133 & .83856 \\
150 & 3.7067 & .99358 \\
150 & 3.6800 & .85389 \\
150 & 3.6667 & 1.10925 \\
150 & 3.6400 & 1.04451 \\
150 & 3.6133 & .88830 \\
150 & 3.6000 & .88991 \\
150 & 3.5800 & .96426 \\
150 & 3.5667 & .99270 \\
150 & 3.5133 & 1.06649 \\
150 & 3.5000 & .98137 \\
150 & 3.4067 & 1.21565 \\
150 & 3.3400 & 1.02210 \\
150 & 3.3067 & 1.29504 \\
150 & 3.2867 & 1.16052
\end{tabular}


I would be very pleased to spend the rest of my career with this organization

Does your outcome match the exertion you have put into your job?

I would not feel it was right to leave my organization even if I got another offer for a better job elsewhere

Have the procedures been free of bias?

I have too much things to do on the job that takes away from my personal interest

Much exhausted to do several things I'd like to do after I come home

\begin{tabular}{|c|c|c|}
\hline 150 & 3.2733 & 1.02908 \\
\hline 150 & 3.1600 & 1.129 \\
\hline 150 & 3.1533 & .994 \\
\hline 150 & 3.0933 & .9922 \\
\hline 150 & 3.0800 & 1.052 \\
\hline
\end{tabular}

Table 4.7: Correlation of WFC and Organizational commitment

\begin{tabular}{|c|c|c|c|}
\hline & & Total_SUM_WFC & Total_SUM_OC \\
\hline \multirow[t]{3}{*}{ Total_SUM_WFC } & Pearson Correlation & 1 & -.062 \\
\hline & Sig. (2-tailed) & & .448 \\
\hline & $\mathrm{N}$ & 150 & 150 \\
\hline \multirow[t]{3}{*}{ Total_SUM_OC } & Pearson Correlation & -.062 & 1 \\
\hline & Sig. (2-tailed) & .448 & \\
\hline & $\mathrm{N}$ & 150 & 150 \\
\hline Iable 4.8: Correlatio & iguity/role conflict and Urganizatio & Total_SUM_RA & Total_SUM_OC \\
\hline \multirow[t]{3}{*}{ Total_SUM_RA } & Pearson Correlation & 1 & $.532^{* *}$ \\
\hline & Sig. (2-tailed) & & .000 \\
\hline & $\mathrm{N}$ & 150 & 150 \\
\hline \multirow[t]{3}{*}{ Total_SUM_OC } & Pearson Correlation & $.532^{* *}$ & 1 \\
\hline & Sig. (2-tailed) & .000 & \\
\hline & $\mathrm{N}$ & 150 & 150 \\
\hline
\end{tabular}

Table 4.9: Correlation of Organizational Injustice with Organizational Commitment

\begin{tabular}{|c|c|c|c|}
\hline & 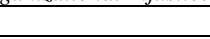 & Total_SUM_OI & Total_SUM_OC \\
\hline \multirow{3}{*}{ Total_SUM_OI } & Pearson Correlation & 1 & $.458^{* *}$ \\
\hline & Sig. (2-tailed) & & .000 \\
\hline & $\mathrm{N}$ & 150 & 150 \\
\hline \multirow{3}{*}{ Total_SUM_OC } & Pearson Correlation & $.458^{* *}$ & 1 \\
\hline & Sig. (2-tailed) & .000 & \\
\hline & $\mathrm{N}$ & 150 & 150 \\
\hline
\end{tabular}

Table 4.10: Model Summary

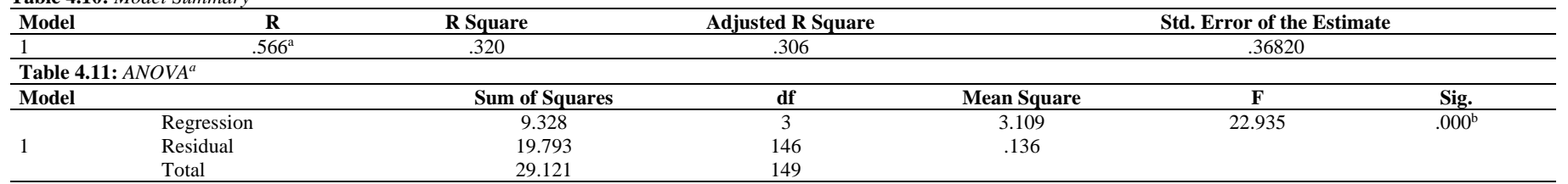

\section{Table 4.12: Coefficients $^{a}$}

\begin{tabular}{|c|c|c|c|c|c|c|}
\hline \multirow{2}{*}{ Model } & & \multicolumn{2}{|c|}{ Unstandardized Coefficients } & \multirow{2}{*}{$\begin{array}{c}\text { Standardized Coefficients } \\
\text { Beta } \\
\end{array}$} & \multirow{2}{*}{$\mathrm{T}$} & \multirow{2}{*}{ Sig. } \\
\hline & & $\mathrm{B}$ & Std. Error & & & \\
\hline \multirow{4}{*}{1} & (Constant) & 1.855 & .240 & & 7.734 & .000 \\
\hline & Total_SUM_WFC & .098 & .040 & .189 & 2.462 & .015 \\
\hline & Total_SUM_RA & .275 & .065 & .432 & 4.247 & .000 \\
\hline & Total_SUM_OI & .113 & .054 & .223 & 2.077 & .040 \\
\hline
\end{tabular}

Table 4.13: Reliability Statistics Cronbach's Alpha

\begin{tabular}{ll}
\multicolumn{1}{c}{.755} & .744 \\
\hline Table 4.14: Summary & 27 \\
\hline Hypothesis & Decision \\
\hline H1: Work-Family conflict has significant relationship with organizational commitment. & Accepted \\
H2:Role Ambiguity/ Role Conflict has significant relationship with organizational commitment & Accepted \\
H3: Organizational injustice has significant relationship with organizational commitment & Accepted \\
\hline
\end{tabular}

